\title{
AN ANALYSIS OF THE TRANSFORMATIONAL LEADERSHIP THEORY
}

\author{
M. Moradi Korejan ${ }^{1, *}$ and H. Shahbazi ${ }^{2}$ \\ ${ }^{1}$ Department of Accounting and Management, Rasht Branch, Islamic Azad University, Rasht, Iran \\ ${ }^{2}$ Department of Agricultural Economics, Sayyed Jamaleddin Asadabadi University, Hamedan, Iran
}

Published online: 15 May 2016

\begin{abstract}
In the fast changing world, organizational leadership becomes more important and it is considered as a critical success factor. In this regard, not only top-level managers need to show their capabilities, but all managers at all levels of the organization also feel the need to cooperate with others to achieve the desired results. Regardless of their job, they should know how to influence others, provoke them into working and also they must take responsibility for outcomes. Transformational leadership refers to leaders who seek to create ideas and new perspectives to create a new path of growth and prosperity in front of the organization. By developing commitment, passion and loyalty among managers and staff, they mobilize organization's members to make fundamental changes in fundaments and basis of the organization in order to be prepared and to gain necessary capabilities for moving in new directions and reaching higher ideal performance peaks.
\end{abstract}

Author Correspondence, e-mail: moradi24442@yahoo.com

doi: http://dx.doi.org/10.4314/jfas.v8i3s.192 
Transformational leader is inspiring and creative and leads people in a way that they try more than their abilities in the organization and also invent and innovate in their work area. Scholars and theorists believe that transformational leadership management is more effective than pragmatic leadership. Transformational leaders make their employees realize the value of what they do.

Keywords: Transformational leadership; idealized influence; intellectual stimulation; inspirational motivation; personal considerations.

\section{ANALYSIS OF THE TRANSFORMATIONAL LEADERSHIP THEORY}

Nowadays, organizations need to increase their knowledge and awareness about the environment and to create wide organizational changes for survival and development. In this context, the role of leaders who move the organization toward the future, recognize the environmental need and facilitate appropriate changes, becomes more evident. Such leaders are called transformational leaders. These leaders can strengthen the staff understanding and justice, and improve the quality of work life in the organization. Quality of work life includes any improvement in organizational culture which improves employees' satisfaction and human dignity and causes their development and growth in the organization. On the other hand, perception of discrimination and injustice demoralizes and demotivates employees and decreases productivity of their performances. In the very fast changing world, organizational management becomes important more than ever and is considered as critical success factor in organizations. Not only top-level managers need to show their capabilities, but all managers at all levels of the organization also feel the need to cooperate with others to achieve the desired results. Regardless of their job, they should know how to influence others, provoke them into working and also they must take responsibility for outcomes. Transformational leadership is a complex and dynamic process in which leaders influence their followers' values, beliefs and goals. These leaders move organizations toward the future, recognize environmental needs and facilitate appropriate changes. They also create perspectives of potential opportunities for employees and develop commitment to change, culture 
improvement and the need to design new strategies for efficiently use of energy and sources (Avarsin et al, 2012, p.23).

\section{THE CONCEPTS OF LEADERSHIP AND TRANSFORMATIONAL LEADERSHIP}

Leadership is emerged from the advent of social life. Some people are put together and begin their social life and influence each other. Transformational leadership is achieved when leaders and followers motivate each other for higher motivation and morality. These leaders have better relationships with their supervisors. They help the organization more than leaders who act transactional and they create more value for the organization. Transformational leaders motivate their employees to do more than what is sited in their employment contract and they focus on the employees' higher level needs. These leaders act as mentors and advisors and pay attention to personal development, learning, and supplying the needs of the employees. They provide challenge, a sense of mission, broader perspectives, respect, and trust for the employees, and they act as role models for their employees. They create an atmosphere of trust and motivate employees to work for the organization beyond their self-interests (Khorshid \& Pashazadeh, 2014, p. 7).

Transformational leadership refers to leaders who seek to create ideas and new perspectives to create a new path of growth and prosperity in front of the organization. By developing commitment, passion and loyalty among managers and staff, they mobilize organization's members to make fundamental changes in fundaments and basis of the organization in order to be prepared and to gain necessary capabilities for moving in new directions and reaching higher ideal performance peaks (Mirkamali et al., 2014, p.23).

The transformational leader constantly looks for potential motives in followers and aims to draw followers' attention to superior needs and conversion of individual interests into collective interests. According to Bass and Avolio, transformational leadership is a conscious, moral and spiritual process that provides development patterns for organization through a reliable equal power leadership. Transformational leaders explain organization's future prospects and provide 
the model consistent with the prospects, improve acceptance of group goals, provide a wide range of support for individuals in the organization and encourage them to pursuit organization's goals (Mortazavi and Nikkar, 2014, p105).

\section{IMPORTANCE AND NECESSITY OF TRANSFORMATIONAL LEADERSHIP}

In the current era, change processes and diversity of instruments used in our daily life increase every day. Changes are happening so fast that no human being, even in the last century, could anticipate them. Global competition and growing business in East and West, in developed and developing countries, have created a highly unstable environment for all businesses. To deal with this uncertain environment and continuous changes, leaders are strongly needed. The world needs transformational leaders. Transformational leadership actions enable organizations to improve their performance in a turbulent and unpredictable environment. When transformational leadership components complement other leadership actions, it can become a source of competitive advantage for organizations. Use of this competitive advantage can be a significant help in strategic competition and earning higher returns in short-term and long-term. In fact, without an effective transformational leadership, the probability that organization be able to face global economic challenges, in order to achieve superior and satisfactory performance, will be reduced (Eskandari, 2014, p. 124).

Importance of leadership in change management process has been emphasized by the fact that this change requires a new system and institutionalizing new approaches. Undoubtedly, behavior and leadership style of a manager have significant impact on type of needs and awareness of staff. Reaction and attitude of the organization members to organizational changes and their attempt to choose support, or resist to organizational changes depend largely on leadership style of a leader as a model of his/her sustainable behavior. (Farazja and Khademi, 2010, p. 51). 


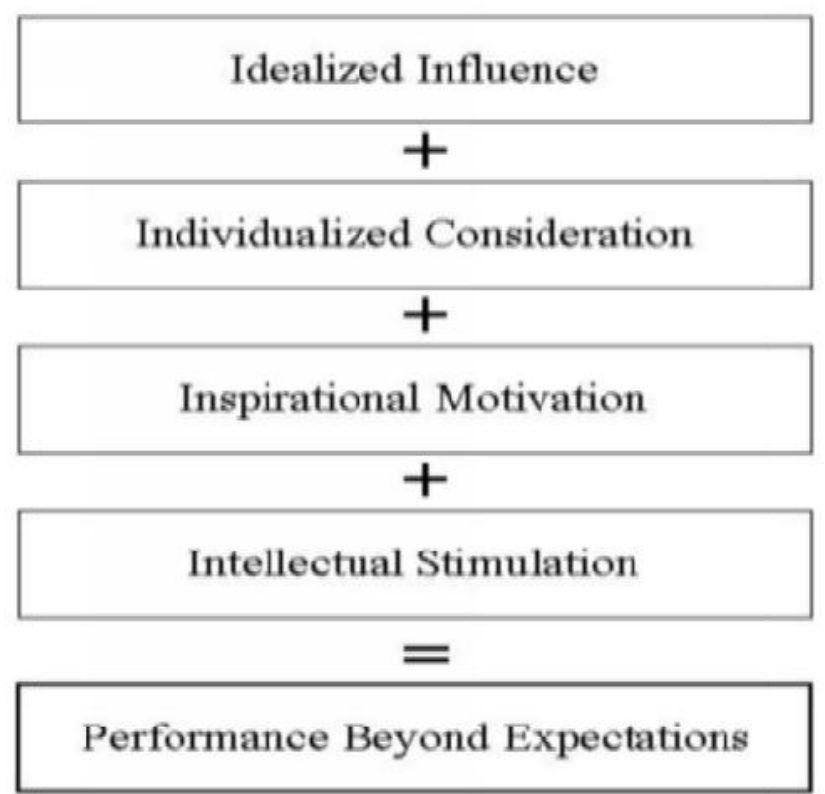

\section{CHARACTERISTICS OF TRANSFORMATIONAL LEADERS}

1. In this kind of leadership, people can affect counterparts and superiors like their subordinates.

2. The process of transformational leadership roots in values and personal beliefs of the leader. However, in this process, goods are not exchanged between superiors and subordinates.

3. Such leaders are inspired by their deepest personal values (like justice, fairness, honesty, and honor). Burns remembered these values as ultimate values. Ultimate values are so that one cannot bargain over them or exchange them.

4. By delivering ultimate values as personal standards, transformational leaders create harmony and unity among their followers and more importantly, they arrange changes in goals and personal beliefs of followers in line with organizational goals (Eskandari, 2014, p. 126).

5. Transformational leadership is inspired from heart and mind and shows them.

6. Transformational leadership has a perspective and links that perspective with passion and purpose. Transformational leader allows his/her feeling to talk to others in a way beyond the mind from depths of its entity. 
7. Transformational leadership pays attention to staff's personal attentions to use them and create trust and commitment. It is about caring staff, what they want, and how you can help them.

8. Transformational leadership refers to obtain a great power through the mind. Mind becomes curious, becomes open to new ideas and learns constantly (steven corey, 2007, p.10).

9.

\section{TRANSFORMATIONAL LEADERSHIP EXPERTS}

The theory of transformational leadership was first proposed by Burns (1978) to distinguish those leaders who have strong motivational relationship with their followers and subordinates and those who widely focus on exchange with transformational leadership interaction to create results. Transformational leadership is a conscious, moral and spiritual process which provides patterns of equal power relationships between leaders and followers to achieve a collective goal or real transformation. Transformational leadership is the process of creating commitment to organizational goals and empowering people to fulfill those goals. Transformational leadership helps and encourages followers to increase their creativity and self-actualization level to encourage team, group, and organizational interests. A transformational leader induces change in the whole organization and creates a perspective for both managers and staff. (Arabiun et al.,2014, pp. 57-56).

\section{FACTORS AFFECTING TRANSFORMATIONAL LEADERSHIP}

Transformational leaders recognize the needs of organization and staff and also stimulate and provide higher level needs inside a person. Transformational leader encourages people to be unified in order to pursuit higher goals with the aim of a positive important change in an organization. Transformational leadership consists of 4 main dimensions: The impact of idealized influence, inspirational motivation, intellectual stimulation and personal considerations (Krista Hoffmeister et al, 2012, p. 69). 
1. Inspirational motivation: Inspirational and motivational leaders are those who challenge their followers in their jobs and create a clear perspective to reach goals and go toward the future by increasing efficiency in the workplace.

2. Individualized consideration: Leader behaves with his/her subordinates according to their own characteristics and capabilities. Leader pays personal attention to individuals in order to develop a healthy relationship by providing new learning opportunities according to their interest and skills.

3. Intellectual stimulation: Leaders encourage their subordinates to try to create motivation and creativity by modifying approaches and opportunities of their own subordinates. The main purpose of the leader is offering free flow of ideas and imaginations so that their followers and subordinates try to reach new techniques and approaches.

4. Idealized influence: Leaders become model for their followers by their friendly behavior. They admire, respect, and trust their followers. They pay more attention to the needs of their followers than their own needs, and avoid using the power for personal interests (Aneja Deveshvar, 2014, p. 178).

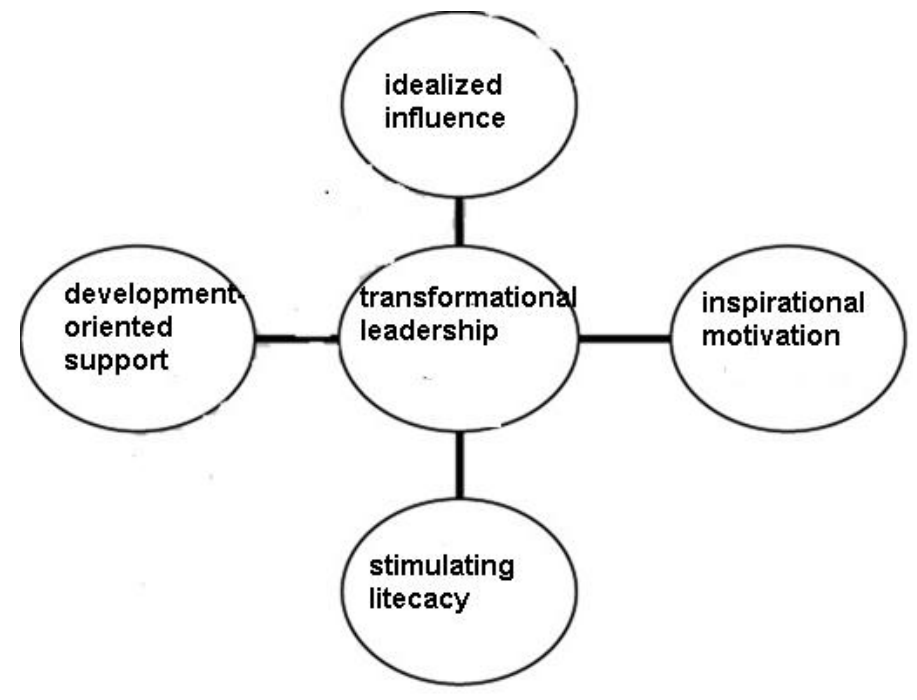

Dimensions and indicators of transformational leadership from the perspective of Bass and Avolio have been summarized in Table B1. 
Table 1. Dimensions of Transformational Leadership from the Perspective of Bass and Avolio

\begin{tabular}{|c|c|}
\hline Dimensions of transformational leadership & Indicators \\
\hline \multirow{5}{*}{ Idealized influence } & Instilling a sense of pride and honor to members \\
\hline & to connect with others \\
\hline & Showing a sense of power and competence \\
\hline & Act in a way to rise other's respect \\
\hline & Sacrificing personal interest for other's interest \\
\hline \multirow{5}{*}{ Inspirational motivation } & Talking optimistically about the future \\
\hline & Talking seriously about things that should be \\
\hline & done \\
\hline & Emphasizing on the importance of foresight \\
\hline & Giving hope to members about achievable goals \\
\hline \multirow{7}{*}{ Intellectual stimulation } & Careful examination of offers to ensure their \\
\hline & suitability \\
\hline & Taking into account different perspectives while \\
\hline & solving a problem \\
\hline & Requesting for examination of problems from \\
\hline & different perspectives \\
\hline & Suggesting new ways of how to do something \\
\hline \multirow{4}{*}{ Personal consideration } & Allocating time for guidance and training \\
\hline & $\begin{array}{l}\text { Treating with members as a person not as a } \\
\text { member }\end{array}$ \\
\hline & Considering people with different needs, abilities \\
\hline & and creativities \\
\hline
\end{tabular}

Help others to develop their capabilities

Resource: (Rezazadeh \& Azizi, 2013) 


\section{RESULTS}

Leadership has always been considered as one of the most important factors of success and failure in any organization and numerous researches have been conducted in this field. In recent decades, transformational leadership has attracted lots of attentions to itself. Transformational leaders employ their personal abilities to promote ideals of others and transfer individuals to higher level of performance. Transformational leaders play critical role in organizational performance. In other words, whatever characteristics of transformational leadership are evident, members will be more encouraged to enhance organization's performance. Because transformational leaders make people motivated. Obviously, when leaders have great personalities, pay attention to individual differences and high level needs of people and provide mental stimulation, thereby, they increase members' involvement and their tendency to make greater effort to succeed and create high-performance in the organization.

\section{REFERENCES}

[1] Arabiun, A., Dehghan Najm abadi, A., Rezazadeh, A., \& Haji Fathali, A. (2014). Investigating the effect of entrepreneurial orientation on the relationship between transformational leadership and organizational performance. Journal of Research in Educational Administration, 5(1), 56-57.

[2] 2-Covey, S. (2007). Transformational leadership report, p. 10.

[3] Deveshwar, A., \& Aneja, I. (2014). A study of transnational and transformational leadership styles and factors affecting the leadership style. International Journal of Business, Economics and Management, 1(8), 176-185.

[4] Eskandari, M. (2014). Analysis and criticism on transformational leadership. pp. 124-126.

[5] Farazja, M., \& Khademi, M. (2011). The relationship between transformational leadership styles and interactionalist and attitudes towards organizational change. Journal of Educational Science, 6(4), 49-70. 
[6] Hoffmeister, A., Alyssa, M., Gibbons, A., Stefanie, K., Johnson, B., Konstantin, P., Cigularov, C., \& Chen P., Y. (2014). The differential effects of transformational leadership facets on employee safety. p. 69.

[7] Khorshid, S., \& Pashazadeh, A. (2014). The effect of transformational leadership on organizational learning capabilities with respect to the mediating role of organizational intelligence, Journal of Change Management, 6(11), p.7.

[8] Maleki Avarsin, S., Hosseini Nasab, D, \& Vafaju, M. (2012). Investigating the relationship between emotional intelligence and transformational leadership style of heads of departments in $13^{\text {th }}$ district in Shiraz Azad University. Journal of Educational Science, 5(18), p. 43.

[9] Mirkamali, M., Shateri, K., \& Uzbashi, A. (2013). Explaining the role of transformational leadership in the field of organizational creativity, Journal of Innovation and Value Creation, 2, p. 23.

[10] Nazeriani, M. A. (2011). Transformational leadership style in organizations. Journal of Nafte-Pars, pp. 5-6.

[11]Nikezić, S., Purić, S., \& Purić, J. (2012). Transactional and transformational leadership development through changes, pp. 288-290.

[12] Rezazadeh, A., \& Azizi, GH. (2012). The impact of transformational leadership on entrepreneurial orientation of organizations (case study: representatives of insurance companies of Yazd Province), News in the World of Insurance. 172, p. 32.

\section{How to cite this article:}

Moradi Korejan M and Shahbazi H. An analysis of the transformational leadership theory. J. Fundam. Appl. Sci., 2016, 8(3S), 452-461. 